\title{
Total Visual System Assessment- Integrating Wavefront Technology in Refractive Examinations
}

\author{
Cynthia Matossian, MD, FACS ${ }^{1}$ and Joseph C Noreika, MD² \\ 1. Matossian Eye Associates, Pennington, New Jersey, US; 2. Excellence In Eyecare Inc., Medina, Ohio, US
}

\begin{abstract}
Current trends and recent legislative changes have increased the pressure to control healthcare costs, especially those associated with running ophthalmic practices. These factors have driven practice consolidation, reduced consultation times, increased use of electronic health record systems, and encouraged more meaningful use of technology. At the same time, patient expectations and standards of clinical care are both rising. This climate could discourage investment in new technology and encourage increased intensity of service, with higher patient throughput at the risk of decreased quality of care. This situation emphasizes the traditional value proposition model in which quality, time, and cost are closely interrelated; decreasing time and/or cost negatively affects quality. The use of wavefront technology and the development of the XFractionSM process, however, have challenged this model. Using the Optical Path Difference III (OPD-III) and Total Refractive System-5100 (TRS-5100), substantially greater amounts of higher-quality data are derived from ophthalmologic patients in shorter examination times than with other refraction instruments. Their use provides an improved patient experience, greater patient throughput, and more time for the physician to precisely tailor the treatment to match the condition. In practices that have acquired the OPD-III, it has become indispensable in vetting patients for intraocular lenses (IOLS), advanced corneal refractive surgery, and preoperative identification of various optical issues. Experience at an example practice shows that optional use of OPD-III examination is high and it is increasing, despite patients incurring out-of-pocket fees. XFraction technology, therefore, is a route to more satisfied patients, greater efficiency, and profitability; and it can help ophthalmic practices thrive amid increasingly adverse commercial and medical pressures.
\end{abstract}

\section{Keywords}

Optical path diagnostics, wavefront optimized refraction, total visual assessment, intraocular lens selection, sustainability, value proposition, return on investment

Disclosure: Cynthia Matossian, MD, FACS, and Joseph C Noreika, MD, have nothing to disclose in relation to this article.

Acknowledgements: Medical writing assistance was provided by James Gilbart at Touch Medical Media, London, and funded by Marco.

open Access: This article is published under the Creative Commons Attribution Noncommercial License, which permits any noncommercial use, distribution, adaptation, and reproduction provided the original author(s) and source are given appropriate credit.

Received: February 22, 2016 Accepted: March 16, 2016 Citation: US Ophthalmic Review, 2016;9(1):41-5

Correspondence: Joseph C Noreika, MD, Excellence In Eyecare, Inc., 3609 Medina Road, Medina, OH 44256, US. E: jcnmd@aol.com; Cynthia Matossian, MD, FACS, Two Capital Way, Suite 326, Pennington, NJ 08534. E: cmatossian@matossianeye.com

Support: The publication of this article was supported by Marco. The views and opinions expressed are those of the authors and not necessarily those of Marco

This review examines how the adoption of refractive wavefront technology can help address the challenges, and promote the success of practices competing in an increasingly demanding regulatory and economic environment. In ophthalmology there is an increased need for efficiency and productivity, beginning with the collection of meaningful patient data. A new value proposition has evolved to meet the demands of changing market conditions. This proposition helps define and protect the value of the practice, drives the decision to acquire new technology and illuminates the procedural changes that add value for the patient, the ophthalmologist, and the business. Devices acquired by a practice need to meet this new paradigm. The metrics proposed below delineate this purchase decision process.

Increased spending mandated by the Affordable Care Act has enhanced access to medical care for people who previously had no medical insurance. ${ }^{1}$
Significant consolidation of the insurance industry has resulted. The cost of insurance policies and out-of-pocket costs to the patient have increased. As a consequence, there is increasing pressure to control these outlays. Practices may respond to the downward pressure on reimbursement by reducing investment. Recent legislation, including the repeal of the Medicare Sustainable Growth Rate (SGR) has shifted the payment model from fee-for-service to value and quality. ${ }^{2-5}$ Medicare payments are now determined by the quality and efficiency of rendered care.

In all areas of medicine, including eye care, there is an impetus to utilize electronic medical record technology in 'meaningful' ways. ${ }^{6-8}$ The meaningful use of electronic health record (EHR) systems aims to engage patients in their healthcare, improve coordination among caregivers and enhance public health. Diagnostic instruments that functionally integrate 
Table 1: Categories of Return on Investment for Ophthalmic Technology and Related Benefits

\begin{tabular}{|c|c|}
\hline $\begin{array}{l}\text { Category of Return } \\
\text { on Investment }\end{array}$ & Related Benefits \\
\hline Direct & Procedures directly reimbursed \\
\hline Indirect & $\begin{array}{l}\text { Improved efficiency } \\
\text { Increased productivity } \\
\text { Decreased cost per exam } \\
\text { Increased number of exams }\end{array}$ \\
\hline Additional & $\begin{array}{l}\text { EHR connectivity } \\
\text { Rx accuracy/decreased re-makes } \\
\text { Triage speed } \\
\text { Diagnostic speed } \\
\text { Diagnostic accuracy } \\
\text { Improve IOL matching (selection) } \\
\text { Increased patient satisfaction } \\
\text { Retention and Referrals } \\
\text { Improved patient experience } \\
\text { Quicker and more effective patient education } \\
\text { Staff retention } \\
\text { Practice differentiation } \\
\text { More competitive in joining plans (ACO, etc.) }\end{array}$ \\
\hline
\end{tabular}

$\overline{A C O}=$ accountable care organization; $E H R=$ electronic health records; $I O L=$ intraocular lens; $R x=$ treatment.

with EHR systems enable sharing of data and images, seamlessly promoting patient interaction and practice efficiency.

There is a trend toward consolidation of providers into group practices such as 'accountable care organizations.' ${ }^{\prime 9}$ This has led to organizations exhibiting greater power to negotiate costs with contracted providers. A separate challenge is associated with the conversion from the International Classification of Diseases-9 (ICD-9), which has been used since 1975, to ICD-10, which was implemented in October 2015. 10-12 A common theme of these changes is the need for capture, documentation, and sharing of complete and reliable data at the point of care.

\section{The Business of Ophthalmology}

There is a dialectic between the acquisition and maintenance costs of new technology and healthcare economics. ${ }^{13}$ One approach is to purchase specific devices that can diagnose or treat as many patients as possible to reduce the per-patient cost of the investment. An important dilemma involves the question of whether to adopt the new technology early or wait until the technology is more widely disseminated and possibly less expensive. Analysis of a technology's true cost must consider the value added for the patient by expansion of the ophthalmologist's diagnostic capabilities. Because of the decreasing reimbursement, the availability and utility of the technology is paramount to ensure a return on investment (ROI).

The profitability of medical practice is dictated by the number of patients examined, the income generated per patient as determined by the intensity of services provided, and the costs associated with providing these services. The enhanced productivity of integrated wavefront analysis and digital refractive technology embraces all three economic parameters.

Fixed costs including staff, rent, leases, and office equipment account for $70 \%$ or more of total practice expenditures. Additional variable costs include intraocular lenses, surgical devices and supplies, small instruments, pharmaceuticals, and utilities. ${ }^{14,15} \mathrm{~A}$ sunk cost, the purchase of new technology also incurs the ongoing cost of its maintenance. Depending on the terms of purchase, this maintenance fee may be a fixed or variable cost.

A practice will typically finance the purchase of expensive technology. ${ }^{16}$ The new equipment must have reasonable initial and operational costs, relative to the benefits it provides. Benefits can include acquisition of additional pertinent data to enhance diagnostic acumen, reduced time to an accurate diagnosis, ease of use, faster staff adoption, reliability, and timely support from the manufacturer. It is also desirable that the technology be appealing and impressive to patients and their caregivers. ${ }^{5,13,17-19}$

Quality of outcome is not determined by merely asserting the novelty of an instrument or therapeutic modality. It is necessary to ask what incremental benefit might be expected relative to performance and cost of this technology when compared to competing products. Outcomes must be equal or superior and costs competitive, or at least justifiable. Ophthalmologists face increasing challenges to ensure new technology will support this value proposition. ${ }^{20,21}$ The acquisition of new technology in any ophthalmic practice must also provide a ROI. In ophthalmic practices, ROIs fall into 'direct', 'indirect', and 'additional' categories, each bringing benefits via different routes. These different ROIs and associated benefits are delineated in Table 1.

Claims that technology saves money are not sufficient to justify purchase. Potential savings and economies must be clearly demonstrable and easily understood. Consideration of price, although important, must not compromise data quality or diminish the patient's overall experience. Demographics are changing patient expectations. Standards defining clinical efficiency have been raised progressively and exponentially through the greatest, the boomer, and the millennial generations. These changes are increasing the demand for, and sophistication of, services. ${ }^{22,23}$ Patient expectations must be managed to align realistic therapeutic possibilities and achievable quality metrics. Recognition and discussion of pre-existing conditions that impact a procedure's outcome must occur before surgery to avoid post-operative dissatisfaction inaccurately attributed to technique or choice of therapy. ${ }^{24-26,27}$

\section{The Value Proposition of the Optical Path Difference Scan Technology and Process}

A transformative technology's value is defined by its intersection with quality, speed, ease of use, and cost delivered to the ophthalmologist, the practice, and most importantly, the patient. ${ }^{28}$ Each value proposition is unique and can be graphically represented by the Venn diagram in Figure 1. value is found at the intersection of the three circles.

\section{XFraction and the OPD-III Aberrometer/Corneal Topographer}

Recently, the traditional value proposition model has been challenged. The fusion of Optical Path Diagnostics (OPD-III) and wavefront-optimized refraction (Total Refractive System-5100; TRS-5100) into a diagnostic process termed 'XFractionSM' (XF) challenges the 'equilibrated compromise' of the traditional model. The dynamics of the value proposition represented by the Venn diagram has dramatically shifted. XF increases speed and 
quantity of data capture, while simultaneously improving diagnostic accuracy. The acquisition cost of the data provided is lowered. 29,30

The XF process combines auto-lensometery, integrated wavefront aberrometry, and digital refraction technologies. Using a process distinct from that employed by competing models, data collated from the three technologies are integrated. An exemplary platform for the XF process is the EPIC workstation. This installation combines two devices. The first is the OPDScan III, which combines five functionalities: autorefraction, keratometry, wavefront aberrometry, topography, and pupilometry. The second device is the TRS-5100, an automated, programmable digital refractor utilizing a space-saving chart system within the EPIC's overall design. In comparison with other available offerings, the multimodality EPIC workstation provides a compact footprint, yielding more high-quality data points, thus enabling enhanced point-of-care decision-making. The devices work on the same compact platform table; the collected data is passed seamlessly to the clinic's EHR. Experience shows that, by completely integrating the component devices, five to seven minutes per exam are saved. Both diagnostic and educational capabilities of the OPD produce significant benefit and value to an ophthalmic practice, affecting the decision to adopt this new wavefront optimized refraction technology, as summarized in Figure 2.

The OPD-III aberrometer/corneal analyzer provides important data for all patients, especially those considering cataract surgery. The integration of topography, wavefront aberrometry, and pupilometry in one instrument with a single registration of eye position permits a reliable analysis of the alignment of the elements comprising the patient's optical system. Angle kappa is measured preoperatively and its acquisition can determine the feasibility of multifocal implantation. Other important parameters include: the amount, pattern, and location of astigmatism; pupil size in mesopic and photopic conditions; type, amount, and location of high-order aberrations; and, a point spread function display of current and expected aberrations after cataract removal based on pre-existing corneal factors. In addition, the OPD captures and displays placido disc mires for analysis of corneal surface abnormalities. Tear film quality and instability indicate the possibility of pre-existing disease. ${ }^{31-38}$ Retro-illumination capability allows discovery of tilted or decentered intraocular lenses (IOLS) as well as cortical and subcapsular changes of the crystalline lens. ${ }^{18,29-31}$ Because the OPD system interconnects with most EHR systems, data are transferred quickly and the results of the diagnostic studies can be graphically displayed across many image formats.

Training strategies ensure rapid staff learning and proficiency. Although sophisticated, the technology is user friendly and ophthalmologists report smooth and predictable staff acceptance. Professionally produced webinars that can be accessed at the viewer's convenience heighten the learning experience. Staff with little or no experience can be trained quickly to perform the testing and refractive functions of the EPIC.

\section{XFraction in the Ophthalmic Practice}

To succeed, today's ophthalmic practices feature efficiency as a key operating principle. The use of wavefront optimized refraction/XF augments and complements multiple aspects of practice efficiency, especially improvements in work flow due to the rapidity and convenience of data capture and its subsequent dissemination throughout the clinic.7.18,30,38-44 The EPIC provides the required information where and
Figure 1: The Traditional Equilibrium of Quality, Speed, and Cost-A Relationship that is Changed by Wavefront Optimized Refraction (XFraction)

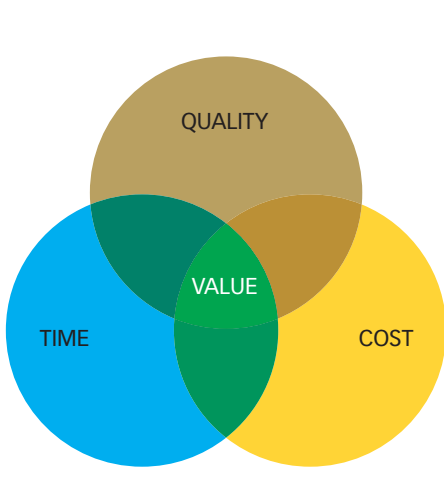

TRADITIONAL

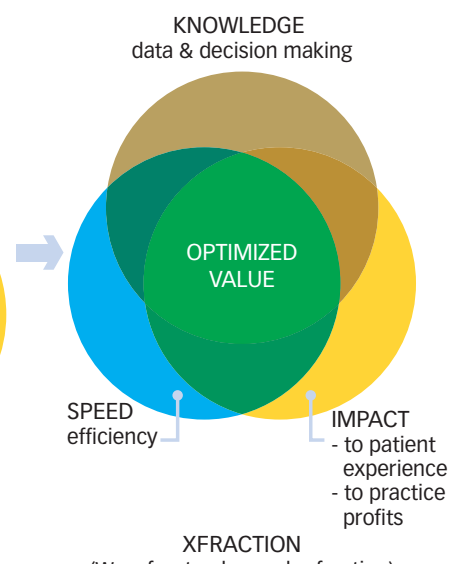

(Wavefront enhanced refraction)

Figure 2: Flow Chart of Factors Affecting the Decision by an Ophthalmic Practice to Adopt Wavefront-optimized Refraction Technology

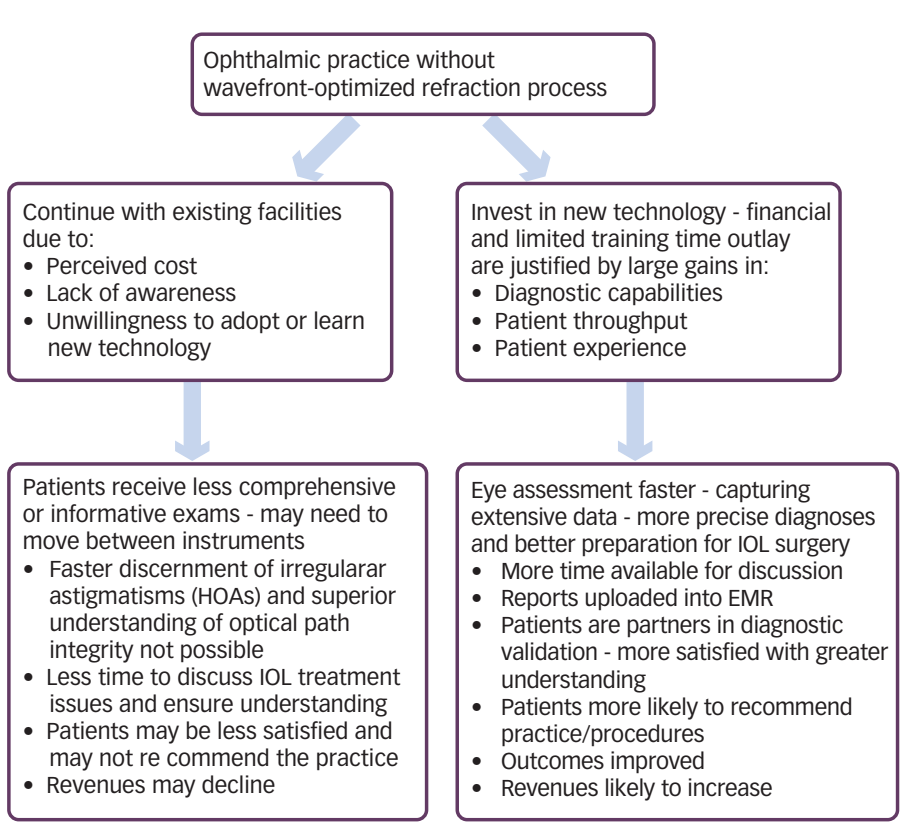

EMR = electronic medical records; HOAs = higher order aberrations, IOLS = intraocular lenses.

when it is needed. In the exam room, its well-organized screens project images to educate the patient, allowing the physician to concentrate on the nuances of the therapy being considered. This saves chair time, while adding value to the patient experience. The value proposition of the EPIC workstation has similarities to those of other innovative and life-changing technologies that are now in widespread public use.

To understand the value proposition that technology and, specifically, the EPIC workstation (OPD-III and TRS-5100 in a combined unit) can bring to an ophthalmic practice, an analogy to the iPhone is insightful. Although most users do not 'need' an iPhone, those who invest in one find it indispensable, for the same reasons that are applicable 
Table 2: Proportions of Cataract Patients of Individual Physicians at an Example Ophthalmic Practice who Opted for Pre-surgical Examination using the OPD-III During Two Separate One-month Periods Two Years Apart (A: October 2013, B: October 2015)

A

\begin{tabular}{lllll}
\hline Physician & $\begin{array}{l}\text { Total Number of Patients } \\
\text { for Cataract Surgery } \\
\text { Testing }\end{array}$ & $\begin{array}{l}\text { Number (\%) of Patients } \\
\text { who Opted for OPD-III } \\
\text { Examination* }\end{array}$ & $\begin{array}{l}\text { Number (\%) of Patients } \\
\text { with Corneal Pathology** }\end{array}$ & $\begin{array}{l}\text { Number (\%) Without Corneal } \\
\text { Pathology and Declined } \\
\text { OPD-III Examination+ }\end{array}$ \\
\hline 1 & $18(42)$ & $6(14)$ & $19(44)$ & 100 \\
\hline 2 & 28 & $1(4)$ & $2(7)$ & $25(89)$ \\
3 & 9 & $5(56)$ & $1(11)$ & 100 \\
\hline
\end{tabular}

B

\begin{tabular}{|c|c|c|c|c|c|}
\hline Physician & $\begin{array}{l}\text { Total Number of Patients } \\
\text { for Cataract Surgery } \\
\text { Testing }\end{array}$ & $\begin{array}{l}\text { Number (\%) of Patients } \\
\text { who Opted for OPD-III } \\
\text { Examination* }\end{array}$ & $\begin{array}{l}\text { Number (\%) of Patients } \\
\text { with Corneal Pathology** }\end{array}$ & $\begin{array}{l}\text { Number (\%) Without Corneal } \\
\text { Pathology and Declined } \\
\text { OPD-III Examination+ }\end{array}$ & Total (\%) \\
\hline 1 & 41 & $36(88)$ & $1(2)$ & $4(10)$ & 100 \\
\hline 2 & 32 & $17(53)$ & $5(16)$ & $10(31)$ & 100 \\
\hline 3 & 19 & $11(58)$ & $3(16)$ & $5(26)$ & 100 \\
\hline 4 & 10 & $3(30)$ & 0 & $7(70)$ & 100 \\
\hline
\end{tabular}

to all transformational technology: short learning curve, ease of use, convenience, support, size, reliability, and utility greater than the sum of its features. A user need not be an expert in the field of information technology to enjoy its benefits. Exquisitely well designed, the iPhone has transformed how we work, research, schedule, remind, communicate, and entertain ourselves. When considering the decision to purchase wavefront technology, the price should not be the determining factor. It is value realized through benefits provided that separate OPD-III and TRS5100 from competing technology. Like an iPhone, the EPIC workstation has the capability of elevating the standard for utility and service in an ophthalmic practice, making it an indispensable component of a state-ofthe-art integrated vision care enterprise.

Adoption of wavefront/XF technology has the potential to increase patient throughput, staff productivity and physician efficiency, all elements that add up to a positive ROI. How a practice captures increased return can be demonstrated by identifying those management metrics impacting practice performance and profitability. While standard reports can be run to monitor time and cost savings, revenue generation, and net profit, other metrics may be more useful. For example, one practice compared its three surgeons relative to patients who opted to pay out-of-pocket for additional pre-operative testing not covered by insurance.

The metrics for OPD-III usage recorded for separate physicians during two one-month periods, in October 2013 and again in October 2015 reveal some interesting trends in OPD-III usage for pre-cataract surgery testing (Table 2). At this practice, patients are asked to pay an out-of-pocket fee for their optional OPD-III examination, which some declined due to not being able to afford it or insisting that they would accept the need to wear glasses after surgery. For patients with corneal pathology, topography examination for their upcoming surgery is reimbursable through health insurance, whereas, for those without such pathology, the cost for this examination cannot be reimbursed. An example is a patient with pre- existing keratoconus prior to cataract surgery testing, for whom the topography is a covered procedure and no out-of-pocket fee would be payable for the topography portion of the OPD-III examination. The results show that between 2013 and 2015, there was a substantial increase in the proportion of patients opting for OPD-III examination. The reason for this is that health insurance providers increasingly expect patients to pay more out-of-pocket costs and more patients consequently accept the necessity to pay. In addition, practice physicians are better able to explain the benefits of OPD-III for more precise implant planning for the larger advanced technology lens options that are currently available. This exercise also revealed that:

- with surgeon $1,93 \%$ of patients chose ancillary testing;

- with surgeon $2,42 \%$ chose it; and,

- with surgeon $3,15 \%$ chose it.

This operational information suggests areas requiring further investigation. Does a surgeon need to invest more time in patient education by fully utilizing the technology and its benefits? Is patient mix significantly different, requiring a customized educational approach during the consultation? Is the investment in additional staff training worthwhile, given the physicians' needs and patient demographics. These analyses are ongoing and may unearth other valuable insights into the operation of the clinic, including determination of true economic return on the practice's investment in equipment. In the future, practices may avail themselves of aggregated 'big data' to aid benchmarking and operational reporting, practice flow analytics, and best practice implementation. This would enable practices to monitor the financial impact of their investment while identifying areas requiring administrative attention based on the real-world experience of multiple other practices.

The OPD-III provides quick, accurate data to help the surgeon individually customize the selection of intraocular lens implant. Because of raised 
expectations, this technology is indispensable in the vetting of patients for premium toric and multifocal implant services and advanced corneal refractive surgery. Pre-operative recognition of ocular surface disease, angle kappa, unrecognized lenticular or irregular astigmatism, corneal spherical aberration, and large mesopic pupils yields better decision-making, more reliable post-operative outcomes and greater patient satisfaction. The use of XF also liberates lost time for superior patient education (using OPD tools). Patients who are better informed because of the educational capabilities afforded by OPD-Scan III have more realistic expectations and are likely to be satisfied after the additional financial outlay that may be required, to achieve an optimal post-operative result.

\section{Conclusion}

The practice of state-of-the-art ophthalmology necessitates the efficient utilization of available technology. Patients must be evaluated and treated quickly yet comprehensively. Information must be available at the point-of-care and succinctly capture the totality of the visual system. Adoption of OPD-III, TRS-5100 and the XF process combining optical path diagnostics and wavefront optimized refractions renders powerful diagnostic information to help meet today's clinical challenges. Patient satisfaction, a key component of the quality of care paradigm, requires the establishment of realistic expectations. Better information leads to greater diagnostic acumen and improved therapeutic decision making. In business, meeting and exceeding a buyer's expectations often confers sustainable competitive advantage. Companies that consistently achieve this show superior customer satisfaction and financial results.
The data from a single ophthalmic practice on usage of the OPD-III in examinations prior to cataract surgery during two one-month periods, two years apart, show that the numbers of patients who opt for this examination are high and increasing. This is despite the examination requiring an out-ofpocket fee that is not covered by their healthcare plans. The increased use likely results from patients recognizing the restrictions imposed on health insurance coverage and are prepared to fund additional procedures personally. In addition, with more experience and understanding of the technology, physicians become better able to explain the benefits of OPD-III examination and make patients understand the improved visual advantages that follow.

Combining optical path diagnostics (OPD-III) and wavefront optimized refractions (with the TRS-5100) creates a powerful means to assess the total visual system. This is especially important to those patients considering cataract surgery. These integrated technologies generate more comprehensive data than traditional, stand-alone diagnostic equipment. This is achieved rapidly without compromising quality. Downward pressure on reimbursement threatens the very existence of the non-efficient, non-competitive provider. The use of optical path diagnostics and digital refraction can improve refractive, clinical and surgical outcomes and maximize patient satisfaction, a key component of competitive advantage and quality of care. Aggregating information, this technology may provide increasingly valuable information to better define future best practices and outcomes. As its utilization becomes widespread, its application will evolve and grow, obviating the problem of obsolescence, a final factor in the consideration of its purchase.
1. Hall MA, Lord R, Obamacare: what the Affordable Care Act means for patients and physicians, BMJ, 2014;349:g5376

2. Cesta T, Case management insider. The new value-based purchasing efficiency measure: are you ready?, Hosp Case Manag, 2014:22:167-70.

3. Ryan AM, Will value-based purchasing increase disparities in care? N Eng/J Med, 2013:369:2472-4.

4. Sangii NF, Repeal of the Sustainable Growth Rate: an overview for surgeons, Am J Surg, 2014;208:597-600.

5. Zhao M, Haley DR, Spaulding A, et al., Value-based purchasing efficiency, and hospital performance, Health Care Manag (Frederick), 2015;34:4-13

6. Boland MV, Chiang MF, Lim MC, et al., Adoption of electronic health records and preparations for demonstrating meaningfu use: an American Academy of Ophthalmology survey, use: an American Academy of Opht

7. Lim MC, Chiang MF, Boland MV, et al., Meaningful use: how did we do, where are we now, where do we go from here? ophthalmology, 2014;121:1667-9.

8. Smith SC, Ophthalmology and meaningful use, Insight, 2012;37:12

Shortell SM, Wu FM, Lewis VA, et al., A taxonomy of accountable care organizations for policy and practice, Health Serv Res, 2014:49:1883-99

10. Kenney D, ICD-10: navigating a successful transition, Md Med, 2014:15:23-4.

11. Manchikanti L, Falco FJ, Hirsch JA, Ready or not! Here comes ICD10, J Neurointerv Surg, 2013;5:86-91

12. Nachimson S, Documentation, documentation, documentation The key to ICD-10 readiness, Md Med, 2014;15:20.

13. Lanzafame RJ, Issues in the acquisition, development, and use of technology in health care, ISLS, 2006:10:401-8.

14. Sheppard SC, A Strategic Look at Case Costs, Ophthalmology Management, 2014:18:5-7,13.

15. Thulasiraj RD, Sivakumar AK, Cost containment in eye care, Community Eye Health, 2001;14:4-6

16. Ophthalmology Management, Acquiring big-ticket ophthalmic equipment, 2011. Available at: www.ophthalmologymanagement. com/articleviewer.aspx?articleID=105841 (accessed June 24, 2015).

17. Gleaton $\mathrm{M}, \mathrm{XFraction}$ process- A rock solid investment in practice growth, Optometric Management, 2014:49:S4-S5.

18. Johnson M, Rosemore R, Deibert C, et al., A Look Inside Four XFRACTIONSM Practices - Four optometrists from across the country share their perspectives on this marriage of autorefraction and aberrometry, Optometric Management, 2013. Available at: www.optometricmanagement.com/articleviewer aspx?articleID=108145: (accessed March 16, 2016)

19. Walia D, Huria J, Cordero I, Equipment maintenance and repair, Community Eye Health, 2010:23:26-9.

20. Clark RT, The value proposition in healthcare, Am J Manag Care,
$2006 ; 12: 645-6$

21. Gupta $R$, The value proposition of health care for the patient, I Neurointerv Surg, 2014;6:721.

22. Erie JC, Baratz KH, Hodge DO, et al., Incidence of cataract surgery from 1980 through 2004: 25-year population-based study, I Cataract Refract Surg. 2007:33:1273-7.

23. Gollogly HE, Hodge DO, St Sauver JL, et al., Increasing incidence of cataract surgery: population-based study, J Cataract Refract Surg, 2013;39:1383-9.

24. North West Eye Surgeons Insight, Managing Patient Expectations After Cataract Surgery, 2013. Available at: www.nweyes.com/ file_viewer.php?id=823 (accessed July 11, 2015).

25. Masket S, Noreika JC, Patient expectations high as level of surgery advances, Ophthalmology Times, 2014. Available at: http:// ophthalmologytimes.modernmedicine.com/ophthalmologytimes/ content/modernmedicine/modern-medicine-feature-articles/ patient-expectations-high?page=full (accessed March 16, 2016).

26. Stephenson $M$, Meeting Expectations in Older Cataract Patients It's less about age, and more about attitude, Review of Ophthalmology, 2013. Available at: www.reviewofophthalmology. com/content/i/2465/c/41660/ (accessed March 16, 2015).

27. Tipperman R, Managing patient expectations, Healio Occular Surgery News, 2011. Available at: www.healio. Occular Surgery News, 2011. Available at. www.healio. surgeon/\%7B6560dae7-ef1b-4b4a-8a5e-58da26223a7e\%7D/ surgeon/\%7B6560dae7-ef1b-4b4a-8a5e-58da26223a7e\%7D/
managing-patient-expectations (accessed March 16, 2016).

28. Hovanesian JA, When considering new technology, think about the three stakeholders, Healio Occular Surgery News, 2014. Available at: www.healio.com/ophthalmology/news/blogs/\%7B200e11eca49b-43ca-80ac-6f4db30644dd\%7D/john-a-hovanesian-md-facs/ when-considering-new-technology-think-about-the-threewhen-considering-new-technology-think-abction

29. Noreika JC, XFraction optical path diagnostix - Exceptiona technology for excellent vision, Optometry Times. Available at: www.modernmedicine.com/sites/default/files/images/digital/OP/ op0914_ezine.pdf (accessed February 20, 2015).

30. Tyson F, Jackson MA, Solomon J, Combining Multimodal Wavefront Examination and Digital Refraction to Create a Rapid and Accurate Approach (XFractionsm) for a Total Visual System Assessment for Intracular Lens Selection, US Ophthalmic Review, 2013:6:110-7.

31. Goldberg L, Riding the Wave: Experts discuss how wavefront aberrometry has transformed refractive correction and consider some of its future applications, Ophthalmolgy Management, 2009. Available at: www.ophthalmologymanagement.com/articleviewe aspx?articleid=103154 (accessed October 9, 2013).

32. Marco, OPD-Scan III, 2010. Available at: www.marco.com/opdscan3 html (accessed August 2, 2013).

33. Ferreira TB, Almeida A, Comparison of the visual outcomes and OPD-scan results of AMO Tecnis toric and Alcon Acrysof IQ toric intraocular lenses, J Refract Surg, 2012;28:551-5.

34. Hida WT, Motta AF, Kara-Jose Junior N, et al., [Comparison between OPD-Scan results and visual outcomes of Tecnis ZM900 and Restor SN60D3 diffractive multifocal intraocular lenses], Arq Bras Oftalmol, 2008:71:788-92.

35. Jackson MA, Complete Data for Choosing IOLS The OPD-Scan III collects and displays key data in minutes for fast, accurate decisions, Ophthalmology Management, 2011. Available at www.ophthalmologymanagement.com/articleviewer. aspx?articleID=106112 (accessed March 16, 2016)

36. Patterson L, Solomon D, Gatinel D, et al., Optimizing Surgical Outcomes with Refractive Wavefront Technology - The OPDScan III gives you the data you need to deliver the exceptional outcomes your patients expect, Optometric Management, 2012. Available at: www.ophthalmologymanagement.com/ articleviewer.aspx?articleID=106960 (accessed March 16, 2016).

37. Rozema JJ, Van Dyck DE, Tassignon MJ, Clinical comparison of 6 aberrometers. Part 1: Technical specifications, J Cataract Refract Surg, 2005;31:1114-27.

38. Solomon JD, Pursuit of perfection how the OPD-Scan III assists me in providing nearly perfect refractive cataract surgery results, Optometric Management, 2011. Available at: www.ophthalmologymanagement.com/articleviewer. aspx?articleid=106111 (accessed March 16, 2016).

39. Collins CM, Salz JJ, Noreika JC, et al., The Thriving Practice: Perfecting cataract outcomes, Ophthalmology Management 2013. Available at: http://docplayer.net/12324565-The-thriving practice.html (accessed March 16, 2016).

40. Cuq C, Lafuma A, Jeanbat V, et al., A European survey of patient satisfaction with spectacles after cataract surgery and the associated costs in four European countries (france, Germany, associated costs in four European countries (france, Germ

41. Quick and easy bottom-line boosters: How our practice bridges the reimbursement gap with new revenue streams, Ophthalmology Management, 2013. Available at: www.ophthalmologymanagement.com/articleviewer. aspx?articlelD=109117 (accessed February 18, 2015).

42. Noreika JC, Practice Perfect: Information Technology Use a Systems-Based Approach to Get the Most Out of Your EMR American Academy of Ophthalmology EyeNet, 2007. Available At: www.aao.org/publications/eyenet/200704/practice_perf.cfm at: www.aao.org/publicatio

43. Pande M, Refractive surprise after cataract surgery, Royal College of Ophthalmologists Update, 2010. Available at: www.rcophth.ac.uk/wp-content/uploads/2014/08/FocusAutumn-2010.pdf (accessed March 16, 2016).

44. Whitman J, The Thriving Practice: A Map to Better Cataract Outcomes, Nidek/Marco, 2013. Available at: www.marco.com/ brochures/thrivesept_whitman.pdf (accessed March, 2015). 